\title{
IT FOR LEAN CONSTRUCTION - A SURVEY IN INDIA
}

\author{
Jyoti Singh $^{1}$, Mohit Mangal ${ }^{2}$ and Jack C.P. Cheng $^{3 *}$
}

\begin{abstract}
Construction is a complex and challenging process consisting of various kinds of waste resulting in client dissatisfaction, cost and time overrun. Waste is defined as a non-value adding component which uses project resources and efforts without achieving any objective. Factors leading to waste in construction are termed as "causes of waste". Current construction practices are unable to eliminate these "causes of waste" due to limited use of technology. This paper presents an IT based methodology to eliminate various "causes of waste" to support lean construction and thereby making the construction process efficient. A questionnaire survey was carried out to investigate major "causes of waste" in the Indian construction industry. 30 major "causes of waste" were identified in the design process, construction planning and site management process, and mal-administration. Literature review helped us identify 13 available IT applications for lean construction. This study aims to link the identified IT applications with relevant "causes of waste" through the developed relationship matrix to mitigate waste causing activities. It was observed that 23 out of the 30 identified major "causes of waste" can be eliminated from 13 identified IT applications.
\end{abstract}

Keywords: Lean Construction, Information Technology, Survey

\section{INTRODUCTION}

The construction industry plays an important role in the development and economic growth of any country. It is a complex and challenging process consisting of various kinds of waste resulting in cost and time overrun, client dissatisfaction, etc.

Waste is defined as a non-value adding component which uses project resources and efforts but does not achieve any objective of the project. Factors leading to waste in construction projects can be termed as "causes of waste". Current construction practices are unable to eliminate these "causes of waste" efficiently due to limited use of information technology (IT) in the construction industry. Hence, there is a need to address and manage the "causes of waste" in an integrated manner to achieve project success in terms of cost, time and satisfaction to clients.

Lean is a philosophy that seeks to eliminate waste in all aspects of production activities in an organization (Womack et al., 1991). It has a very extensive collection of tools and concepts, such as value stream mapping which permits systematic view of value flow process (Pasqualini and Zawislak, 2005), integrated project delivery (IPD) which encourages communication and collaboration among participants (Suttie et al., 2013), last

1 Research Postgraduate Student, Dept. of Civil and Environment Engineering, The Hong Kong University of Science and Technology, Hong Kong, China, +852 5106 4954, jsinghab@connect.ust.hk

2 Research Postgraduate Student, Dept. of Civil and Environment Engineering, The Hong Kong University of Science and Technology, Hong Kong, China, +852 5980 1108, mmangal@connect.ust.hk

3 Associate Professor (Corresponding Author), Dept. of Civil and Environment Engineering, The Hong Kong University, of Science and Technology, Hong Kong, Chinamailto:f.n.bosche@hw.ac.uk, +852 2358 8186, cejcheng@.ust.hk, +852 2358 8186, cejcheng@.ust.hk 
planner system (LPS) which adds value through structuring the planning and ensuring proper flow process (Ballard and Howell, 2003), etc.

Besides various lean tools, IT applications can also help to facilitate lean approach by allowing information flow and storage during the construction process, thereby eliminating various wastes during construction. Implementation of IT in lean construction increases the efficiency of construction projects up to 20\% (Rischmoller and Alarcón, 2005).

Use of IT applications in the construction industry helps to mitigate many "causes of waste" through better connectivity and interoperability. IT helps in easy exchange of data and information between project participants on a regular basis to avoid waste of time and resources. However, as a few information technologies have been advanced at a fast pace, several IT applications have not yet been fully and widely used to support lean construction.

This paper presents an IT based methodology to eliminate various "causes of waste" to support lean construction and thereby making the construction process more efficient. A questionnaire survey was carried out to investigate major "causes of waste" in the Indian construction industry, as the industry is currently blooming with huge potential of waste reduction due to limited use of IT and lean methods in construction practices. Various IT applications currently used in the construction industry are identified via the literature review. The identified IT applications are then linked with relevant "causes of waste" through the developed relationship matrix to mitigate potential waste causing activities.

\section{QUESTIONNAIRE SURVEY IN INDIA}

A questionnaire survey was carried out for the Indian construction industry to find major "causes of waste" in the construction field. The questionnaire was prepared according to the findings of the literature review on "causes of waste". A total of 45 "causes of waste" were selected for the survey. The objective was to find the dominant "causes of waste" generally observed in the construction industry and rank them as per their frequency of occurrence on the construction site. Responses were collected on a five-level Likert scale, which is a common approach to scale responses in survey research, representing the frequency of occurring "causes of waste" according to the respondent.

The questionnaire was sent to the field experts by email or in person. 140 questionnaires were sent in total and 46 responses were received, consisting of 29 contractors, 7 consultants, 4 suppliers, and 6 designers. The work experience of the respondents is shown in Figure 1. It can be seen that the majority of respondents have more than five years of work experience in the construction industry.

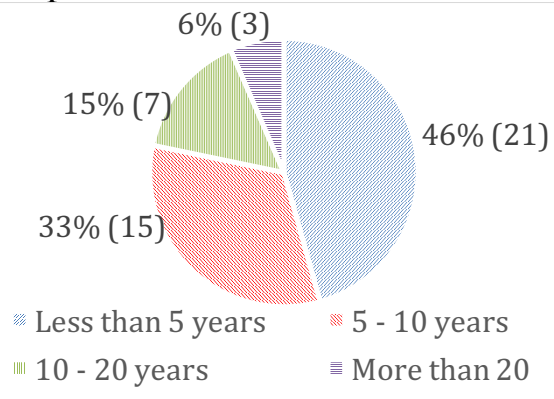

Figure 1: Industry work experience of the survey respondents

No importance was given to 15 "causes of waste" by all the respondents out of total 45 "causes of waste" selected for the survey. The remaining 30 "causes of waste" was recorded for further analysis. 
The collected responses were analysed using Cronbach's alpha test and Relative Importance Index method (RII). The questionnaire survey comprised of different "causes of waste". Therefore, Cronbach's alpha test was performed to check the internal consistency (reliability) of "causes of waste" before further analysis. A Cronbach's alpha value of 0.911 is resulted, showing the strong correlation among the "causes of waste" and thus, "causes of waste" data were reliable for further analysis. RII was then used to rank the "causes of waste" by calculating the weighted average using the formula as given:

$$
\mathrm{RII}=\sum \frac{W n}{(N * A)}
$$

where, $\mathrm{Wn}=$ weights given by the respondent on the Likert scale of 1 to 5

$\mathrm{N}=$ number of respondents

$\mathrm{A}=$ the highest weight assigned, (5 in the current case)

Table 1: RII and rank of the "causes of waste" identified in survey

\begin{tabular}{|c|c|c|c|}
\hline Rank/No. & Attributes & RII & Identified Group \\
\hline 1 & Unnecessary work & 0.821 & II \\
\hline 2 & Rework & 0.815 & II \\
\hline 3 & Poor planning and co-ordination of resources & 0.785 & II \\
\hline 4 & Lack of proper supervision & 0.769 & II \\
\hline 5 & Poor communication among team members & 0.764 & II \\
\hline 6 & Waiting time & 0.749 & II \\
\hline 7 & Lack of transparency & 0.749 & III \\
\hline 8 & $\begin{array}{l}\text { Inadequate time given for planning and design } \\
\text { stage }\end{array}$ & 0.744 & I \\
\hline 9 & Design changes by clients & 0.744 & I \\
\hline 10 & $\begin{array}{l}\text { Lack of team work and co-ordination between } \\
\text { parties }\end{array}$ & 0.718 & III \\
\hline 11 & Insufficient quality & 0.718 & II \\
\hline 12 & Improper documentation of design data & 0.692 & I \\
\hline 13 & Excessive inventory & 0.692 & II \\
\hline 14 & Use of old techniques & 0.687 & II \\
\hline 15 & Lack of experienced staff & 0.687 & III \\
\hline 16 & Lack of training programs & 0.687 & III \\
\hline 17 & Lack of past project review & 0.682 & I \\
\hline 18 & Lack of skilled manpower & 0.672 & II \\
\hline 19 & Choice of wrong construction methods & 0.667 & II \\
\hline 20 & Lack of risk management plans & 0.662 & III \\
\hline 21 & Poor safety & 0.656 & III \\
\hline 22 & Human error & 0.656 & II \\
\hline 23 & Bureaucracy \& red tape & 0.631 & III \\
\hline 24 & Delay in approval & 0.626 & I \\
\hline 25 & Inferior working conditions & 0.621 & II \\
\hline 26 & Inefficiency of equipment & 0.621 & II \\
\hline 27 & Excessive processing & 0.615 & II \\
\hline 28 & Changes made by regulatory authority & 0.605 & III \\
\hline 29 & Unnecessary movement & 0.590 & II \\
\hline 30 & Scrape waste & 0.585 & II \\
\hline
\end{tabular}


30 "causes of waste". Table 1 shows all selected 30 "causes of waste" categorised as (I) design management waste, (II) construction planning \& site management waste, and (III) mal-administration. As shown in Table 1, the most common waste in the Indian construction as per the field experts mainly follow the category (II) construction planning $\&$ site management waste.

\section{IT BASED APPROACHES}

Based on literature review, some commonly used IT applications in the construction industry with their benefits are summarized as follows:

- (A) Building Information Modelling (BIM) /Virtual Design and Construction (VDC) - Both BIM and VDC share similar characteristics. BIM/VDC helps to improve the efficiency of the design phase, reduce the time taken and quantity take off and increase the percentage planned-complete by a considerable amount. It also increases reliability and visibility through 3D/4D virtual models (Knotten and Svalestuen, 2014).

- (B) Cloud Computing - Cloud computing enables rapid visualization of demand and supply data and helps in instant tracking of construction material status in the supply chain. It also helps in merging and synchronizing multiple sources of information for better communication among various stakeholders (Azambuja et al., 2013).

- (C) Common Data Environment (CDE) - CDE helps to collect, manage, share information and disseminate all relevant documents among various stakeholders (PAS 1192-2, 2013).

- (D) Data Mining - Data mining helps to extract repeated and useful patterns from a large data set to predict the outcome of future events (Danilevsky et al., 2014).

- (E) Geographical Information System (GIS) - GIS provides access to asset data within reasonable time for site feasibility analysis, and efficient use of equipment (Maisuria, 2013)

- (F) GPS Support System - GPS helps in tracking the whereabouts of fleet of assets in order to reduce lead-time at work sites with improved delivery and customer satisfaction (Simonsson and Carlsward, 2005).

- (G) On-Site Vision Tracking - Using closed circuit television (CCTV) effective positioning of personnel in construction sites, activity sequence analysis, enhancing pull flow mechanism, better localization of tools and material, detection of conflicts, visualization of waste and safety on site as well as adequate flow of information throughout the construction process can be supported (Brilakis et al., 2008).

- (H) Radio Frequency Identification (RFID) - RFID provides real-time information of assets, improves visibility and traceability, enhance safety and security of workers, and reduce resource wastage (Lu et al., 2011).

- (I) Robots - Robots provide better productivity under extreme conditions with a high degree of precision, speed of execution, safety, and security (Warszawski, 1986). 
- (J) Simulation - Simulation helps to model uncertainties pertaining to timing, resource assignment, quantity, and flow path. It also helps to examine dynamic system behaviour of the construction process to identify critical disturbances (Gehbauer et al., 2007).

- (K) Tablets and Mobiles - Tablets and Mobiles allow exchange and visualization of real time information of work performance, thereby eliminating waste and pursuing perfection in construction work flow. Fast information flow at low cost, efficient and effective communication, easy monitoring and control on construction progress, and reduced deviation from planned output can be supported (Barbosa et al., 2013).

- (L) Virtual Reality (VR) and Augmented Reality (AR) - VR creates a real-world experience for the end consumer, therefore saving time in developing a prototype and avoid design changes at a later stage. AR streamlines the interaction process for designers, engineers, and builders for fast and better design analysis. It also provides an exact idea of relevant dimensions, size, and shape (Webster et al., 1996)

- (M) Web-Based Information System - web based system can reduce processing time, increase RFI transparency, and improve connectivity among all the team members. They can also, enhance flow reliability, provide the right information at the right moment, and enable better planning and control in construction project (Chin, 2010).

\section{RELATIONSHIP MAPPING MATRIX}

A relationship matrix was used for linking the identified "causes of waste" with available IT applications. It provides the guidelines and direction for mitigating "causes of waste" with the mapped IT applications. Mapping was done by linking the results from the literature review on IT applications as per the benefits it provides to eliminate "causes of waste".

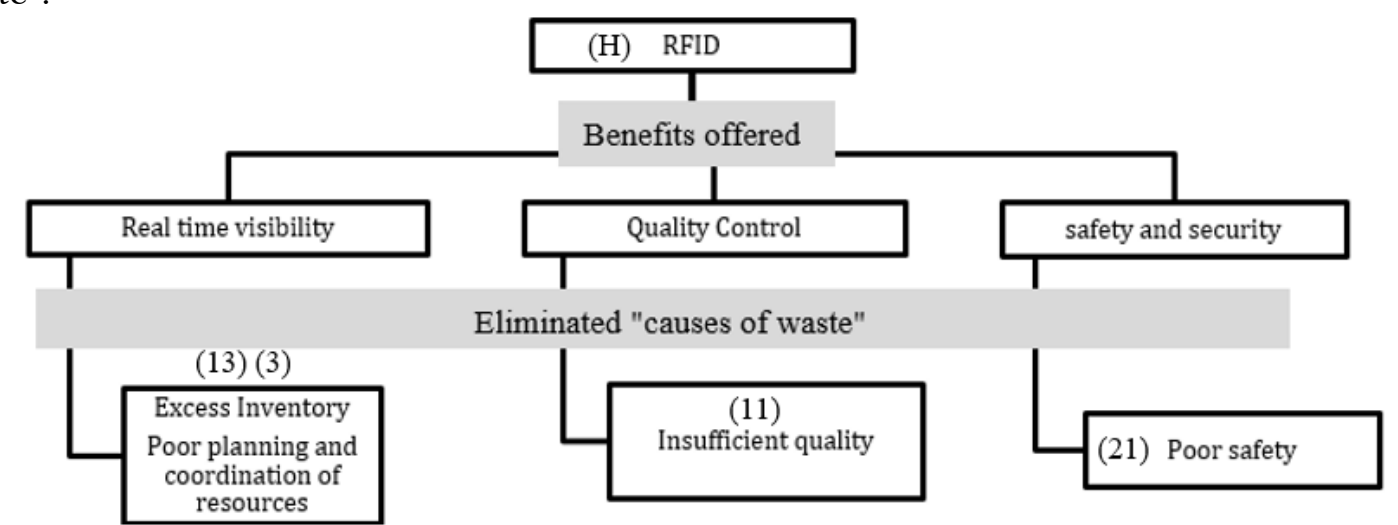

Figure 2: Mapping the benefits of RFID with the "causes of waste eliminated

The Table 2 and Figure 3 below shows the benefits of RFID and those of tablets \& mobiles mapped with "causes of waste" it can eliminate, respectively. Similarly, other IT applications were mapped with the identified "causes of waste", as illustrated in Table 2.

It was observed that 23 out of 30 "causes of waste" can be eliminated with the 13 identified IT applications. The remaining seven "causes of waste" are in the category of mal-administration. Hence, they require management attention and change in various management policies instead. 


\begin{tabular}{|l|l|l|}
\hline Rank/No. & Attributes & IT applications \\
\hline & \multicolumn{2}{|c|}{ (III) Mal-administration } \\
\hline 7 & Lack of transparency & $\begin{array}{l}\text { (A) BIM/VDC; (B) Cloud computing; (C) CDE; (E) GIS; (F) } \\
\text { GPS; (G) On-Site vision tracking; (J) Simulation; (L) VR and AR; } \\
(\text { M) Web-based information system, }\end{array}$ \\
\hline 10 & $\begin{array}{l}\text { Lack of team work and Co- } \\
\text { ordination between parties }\end{array}$ & $\begin{array}{l}\text { (A) BIM/VDC; (B) Cloud computing; (C) CDE; (L) VR and AR; } \\
\text { (M) Web-based information system }\end{array}$ \\
\hline 15 & Lack of experienced staff & \\
\hline 16 & Lack of training programs & \\
\hline 20 & $\begin{array}{l}\text { Lack of risk management } \\
\text { plans }\end{array}$ & (A) BIM/ VDC; (D) Data Mining; (J) Simulation; (L) VR and AR \\
\hline 21 & Poor safety & (G) On-Site vision tracking; (H) RFID; (I) Robots, \\
\hline 23 & Bureaucracy \& red tape & \\
\hline 28 & $\begin{array}{l}\text { Changes made by regulatory } \\
\text { authority }\end{array}$ & \\
\hline
\end{tabular}

\begin{tabular}{|c|c|c|}
\hline Rank/No. & Attributes & IT applications \\
\hline \multicolumn{3}{|c|}{ (I) Design Management Waste } \\
\hline 8 & $\begin{array}{l}\text { Inadequate time given for } \\
\text { planning and design stage }\end{array}$ & $\begin{array}{l}\text { (A) BIM/VDC; (L) VR and AR; (M) Web-based information } \\
\text { system }\end{array}$ \\
\hline 9 & Design changes by client & (A) BIM/VDC; (M) Web-based information system \\
\hline 12 & $\begin{array}{l}\text { Improper documentation of } \\
\text { design data }\end{array}$ & $\begin{array}{l}\text { (A) BIM/VDC; (C) CDE; (L) VR and AR; (M) Web-based } \\
\text { information system }\end{array}$ \\
\hline 17 & Lack of past project review & (D) Data mining; (M) Web-based information system \\
\hline 24 & Delay in drawing approval & (A) BIM/VDC; (C) CDE; (M) Web-based information system \\
\hline \multicolumn{3}{|c|}{ (II) Construction Planning \& Site Management Waste } \\
\hline 1 & Unnecessary work & $\begin{array}{l}\text { (A) BIM/VDC; (G) On-Site vision tracking; (I) Robots; (J) } \\
\text { Simulation; (L) VR and AR }\end{array}$ \\
\hline 2 & Rework & (A) BIM/VDC; (L) VR and AR \\
\hline 3 & $\begin{array}{l}\text { Poor planning and } \mathrm{co}^{-} \\
\text {ordination of resources }\end{array}$ & $\begin{array}{l}\text { (A) BIM/VDC; (B) Cloud computing; (C) CDE; (E) GIS; (F) GPS; } \\
\text { (G) On-Site vision tracking; (H) RFID; (J) Simulation; (K) } \\
\text { Tablets and mobiles; (M) Web-based information system }\end{array}$ \\
\hline 4 & Lack of proper supervision & $\begin{array}{l}\text { (A) BIM/VDC; (B) Cloud computing; (F) GPS; (G) On-Site vision } \\
\text { tracking; (J) Simulation; (L) VR and AR; (M) Web-based } \\
\text { information system }\end{array}$ \\
\hline 5 & $\begin{array}{l}\text { Poor communication among } \\
\text { team members }\end{array}$ & $\begin{array}{l}\text { (A) BIM/VDC; (B) Cloud computing; (C) CDE; (K) Tablets and } \\
\text { mobiles; (L) VR and AR; (M) Web-based information system }\end{array}$ \\
\hline 6 & Waiting time & $\begin{array}{l}\text { (A) BIM/VDC; (B) Cloud computing; (F) GPS; (G) On-Site vision } \\
\text { tracking; (I) Robots; (J) Simulation; (K) Tablets and mobiles }\end{array}$ \\
\hline 11 & Insufficient quality & (H) RFID \\
\hline 13 & Excessive inventory & $\begin{array}{l}\text { (B) Cloud computing; (F) GPS; (G) On-Site vision tracking; (H) } \\
\text { RFID }\end{array}$ \\
\hline 14 & Use of old techniques & \\
\hline 18 & Lack of skilled manpower & (I) Robots \\
\hline 19 & $\begin{array}{l}\text { Choice of wrong } \\
\text { construction methods }\end{array}$ & (A) BIM/VDC; (L) VR and AR \\
\hline 22 & Human error & (B) Cloud computing; (G) On-Site vision tracking; (I) Robot \\
\hline 25 & Inferior working conditions & (G) On-Site vision tracking \\
\hline 26 & Inefficiency of equipment & (G) On-Site vision tracking \\
\hline 27 & Excessive processing & (I) Robots \\
\hline 29 & Unnecessary movement & \\
\hline 30 & Scrap Waste & (G) On-Site vision tracking; (J) Simulation \\
\hline
\end{tabular}

Table 2: Relationship matrix for IT applications and "causes of waste" 


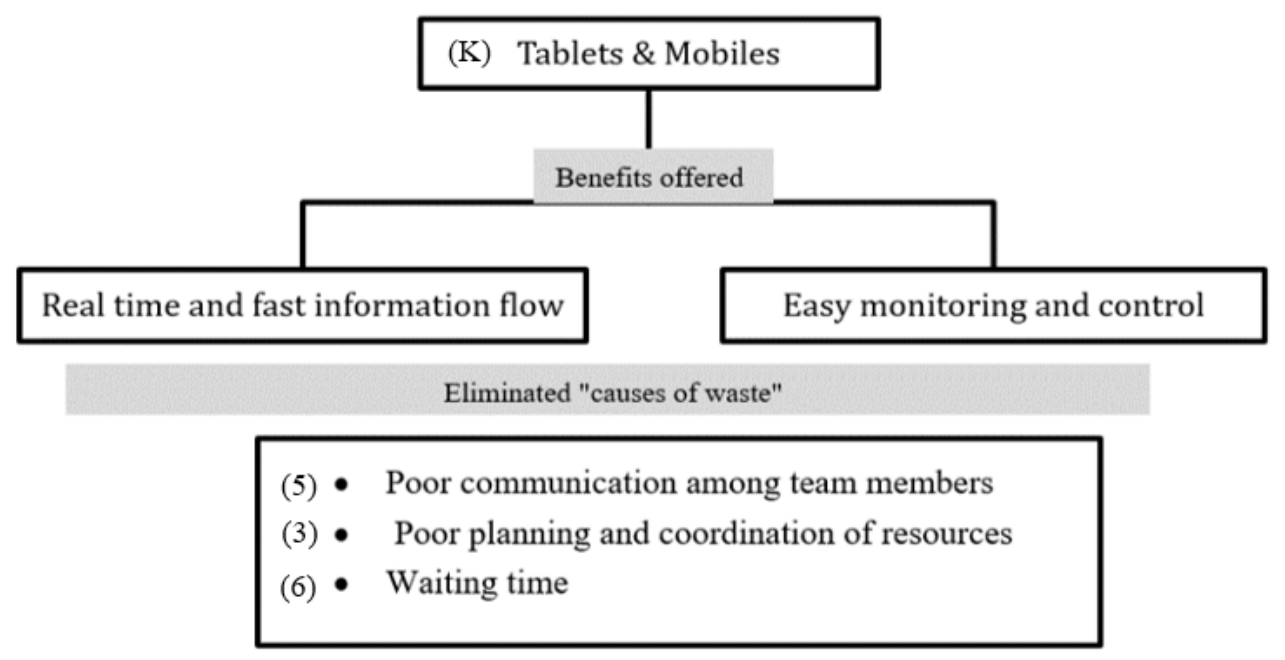

Figure 3: Mapping the benefits of tablets \& mobiles with the "causes of waste eliminated

\section{CONCLUSIONS AND FUTURE WORK}

Past case studies and observations from various construction sites have identified 30 major "causes of waste" in the Indian construction industry. As per questionnaire survey, major "causes of waste" can be categorised into (I) design management related waste, (II) construction planning \& site management related waste, and (III) mal-administration.

13 relevant IT applications satisfying lean perspective were identified through literature review. It was found that 23 out of the 30 major "causes of waste" can be effectively eliminated through the 13 identified IT applications. The remaining seven "cause of waste" require management intervention for their mitigation. Although the questionnaire survey was carried out in India, results are still valid globally due to similar nature of construction processes all over the world.

As per the developed relationship matrix, it was found that the use of IT such as BIM and web-based information systems in construction processes from cradle to gate can effectively share various important information system among the participants and can reduce most of the "causes of waste" with ease. The on-site vision tracking system also helps in reducing site management waste.

The developed relationship matrix is based on the inputs of many experts and provides a good solution to mitigate the common "causes of waste" on construction sites. However, a study is required in the future to develop in-depth knowledge about the interaction of identified "causes of waste" with each other.

\section{REFERENCES}

Azambuja, M., Schnitzer, T., Sahin, M. \& Lee, F. (2013) Enabling Lean Supply with a Cloud Computing Platform - An Exploratory Case Study. The 21st Annual Conference of the International Group for Lean Construction. Fortaleza, Brazil.

Pasqualini, F. \& Zawislak, P. (2005) Value Stream Mapping in Construction: A Case Study in a Brazilian Construction Company. The 13th International Group for Lean Construction Conference: Proceedings. Sydney, Australia. 
Ballard, G. \& Howell, G. (2003) An Update on Last Planner. The 11th Annual Conference of the International Group for Lean Construction. Virginia, USA.

Barbosa, G., Andrade, F., Biotto, C. \& Mota, B. (2013) Heijunka System to Level Telescopic Forklift Activities Using Tablets in Construction Site. The 21st Annual Conference of the International Group for Lean Construction. Fortaleza, Brazil.

Brilakis, I., Cordova, F. \& Clark, P. (2008) Automated 3D Vision Tracking for Project Control Support. The 15th EG-ICE International Workshop. Plymouth, UK.

Chin, C. (2010) RFI Responsiveness of Paper-Based vs. Web-Based Information Processing Systems. The 18th Annual Conference of the International Group for Lean Construction. Haifa, Israel.

Danilevsky, M., Wang, C., Desai, N., Ren, X., Guo, J. \& Han, J. (2014) Automatic Construction and Ranking of Topical Key phrases on Collections of Short Documents.

Gehbauer, F., Zulch, G. \& Ott, M. (2007) Simulation-Based Analysis of Disturbances in Construction Operations. The 15th Annual Conference of the International Group for Lean Construction. Michigan, USA.

Knotten, V. \& Svalestuen, F. (2014) Implementing Virtual Design and Construction (VDC) in Veidekke - Using Simple Metrics to Improve the Design Management Process. The 22nd Annual Conference of the International Group for Lean Construction. Oslo, Norway.

Koskela, L., Howell, G., Ballard, G. \& Tommelein, I. (2002). The Foundations of Lean Construction, Oxford, UK, Butterworth Heinemann.

Lu, W., Huang, G. Q. \& Li, H. (2011) Scenarios for applying RFID technology in Construction Project Management. Automation in Construction, 20 (2).

Maisuria, A. \& Rathod, H. (2013) GIS and its Application in Construction Industry. The International Journal of Advanced Research in Engineering, Science \& management.

Rischmoller, L. \& Alarcon, L. (2005) Using Lean Principles as a Framework to Study Information Technology in Construction. The 13th International Group for Lean Construction Conference: Proceedings. Sydney, Australia.

Simonsson, P. \& Carlsward, J. (2005) Evaluation of a GPS Support System for Fleet Management Control. The 13th Annual Conference of the International Group for Lean Construction. Sydney, Australia.

Specification for information management for the capital/delivery phase of construction projects using building information modelling. PAS 1192-2:2013.

Suttie, J. (2013) The impacts and effects of Integrated Project Delivery on participating organization with a focus on organization culture. The 21st International Group of Lean Construction. Fortaleza, Brazil.

Webster, A., Feiner, S., Macintyre, B., Massie, W. \& Krueger, T. (1996) Augmented Reality in Architectural Construction, Inspection, and Renovation.

Womack, J., Jones, D. \& Roos, D. (1991) The Machine that changed the World: The Story of Lean Production, New York.

Warszawski, A. (1984) Application od Robotics to Building Construction. The 1st International Conference on Robotics in Construction. 